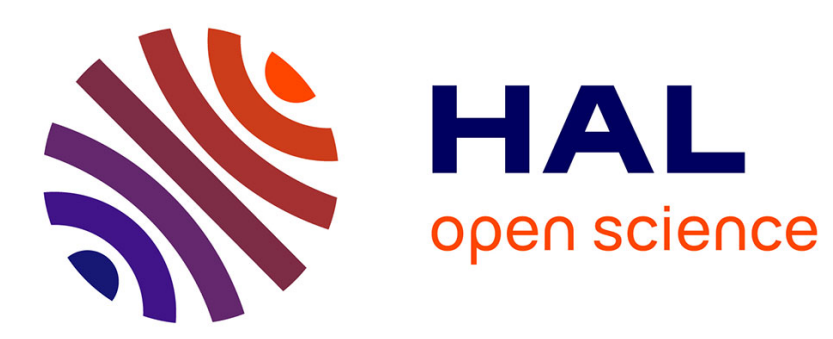

\title{
Emerging ICT concepts for smart, safe and sustainable industrial systems
}

Damien Trentesaux, Theodor Borangiu, André Thomas

\section{To cite this version:}

Damien Trentesaux, Theodor Borangiu, André Thomas. Emerging ICT concepts for smart, safe and sustainable industrial systems. Computers in Industry, 2016, 81, pp.1-10. 10.1016/j.compind.2016.05.001 . hal-01315583

\section{HAL Id: hal-01315583 \\ https://hal.science/hal-01315583}

Submitted on 13 May 2016

HAL is a multi-disciplinary open access archive for the deposit and dissemination of scientific research documents, whether they are published or not. The documents may come from teaching and research institutions in France or abroad, or from public or private research centers.
L'archive ouverte pluridisciplinaire HAL, est destinée au dépôt et à la diffusion de documents scientifiques de niveau recherche, publiés ou non, émanant des établissements d'enseignement et de recherche français ou étrangers, des laboratoires publics ou privés. 


\title{
Emerging ICT concepts for smart, safe and sustainable industrial systems
}

\author{
Damien Trentesaux ${ }^{1}$, Theodor Borangiu ${ }^{2}$, André Thomas ${ }^{3}$ \\ ${ }^{1}$ LAMIH UMR CNRS 8201, University of Valenciennes and Hainaut-Cambrésis, France \\ damien.trentesaux@univ-valenciennes.fr \\ ${ }^{2}$ CIMR, University Politehnica of Bucharest, Romania \\ theodor.borangiu@cimr.pub.ro \\ ${ }^{3}$ CRAN, Lorraine University, France \\ andre.thomas@univ-lorraine.fr
}

\begin{abstract}
This editorial introduces the special issue on Emerging Information and Communication Technology (ICT) concepts for smart, safe and sustainable industrial systems in the Elsevier journal Computers in Industry. The 13 papers in this special issue were selected because of their high quality and also because they propose emerging ICT solutions that address at least one of the three dimensions we suggest are basic requirements to design usable future Industrial Systems that must be safe, smart and sustainable. Previous global discussions about the state of the art with regard to the topic of this special issue are provided, as well as exploratory guidelines for future research in this area.
\end{abstract}

Keywords: safety, smart systems, sustainability, intelligent manufacturing systems, ICT.

\section{Introduction}

This special issue aims at shedding light on new emerging ICT concepts for smart, safe and sustainable industrial systems.

Markets are currently imposing very strict requirements, demanding high-quality customized products with shorter delivery times and shorter lifecycles, forcing companies to adapt their processes with the help of flexible, safe and reconfigurable production structures. This leads to the challenge of designing systems that exhibit better re-configurability, agility, robustness and responsiveness while ensuring the maintainability, sustainability and long-term performances of their processes, products and logistics systems.

In this context, the technological evolutions in ICT have allowed researchers to develop new emerging concepts that were not even conceivable in the past. They are based on the instrumentation and interaction of a multitude of different interconnected and even decision-capable smart objects (belonging to industrial and/or logistics systems), embedded or distant, with associated information counterparts (agents, holons) or purely digital. These "bottom-up" approaches lead to emerging behaviours that must be controlled and integrated with existing, more "top-down" approaches. The latter is often materialized by centralized or hierarchical management systems. These emerging ICT concepts provide new, powerful solutions to challenges as yet unsolved using classical approaches. This special issue focuses on the above challenges and solutions, and especially on the way emerging "bottom-up" behaviours are efficiently and effectively integrated with "top-down" approaches to constitute a kind of hybrid control system with a dynamic structure and distributed intelligence capable of meeting industrial needs and rapid market changes.

The articles included in this special issue concern the following topics of interest and theoretical backgrounds dealing with the lifecycle of smart objects: holonic/multi-agent architectures, computing and service-oriented manufacturing, Cyber-Physical Systems, Intelligent Products, product-driven control, Internet of Things, ambient intelligence, optimization, energy awareness, and self-organized and bio-inspired systems. Some papers in this special issue are extended versions of chapters published in the book edited after the $4^{\text {th }}$ edition of the SOHOMA'14 Workshop on Service 
Orientation in Holonic and Multi-Agent Manufacturing, held in Nancy in November 2014 (Borangiu et al., 2015b).

This editorial is organized as follows: firstly, the context of this special issue is presented, which deals with three dimensions: safe, smart and sustainable. Secondly, the papers composing this special issue are positioned according to their contribution to one or several of the dimensions introduced, and are presented briefly. Perspectives are then introduced as a guideline for future work.

\section{Smart, Safe and Sustainable industrial systems}

From our point of view, to be liveable and usable, future products, processes and industrial systems will be characterized according to three dimensions: Smart, Safe and Sustainable (denoted ' 3 S' hereinafter), as depicted in figure 1. In this figure, some emerging research topics that can be studied at the intersection with any two of the three dimensions are provided.

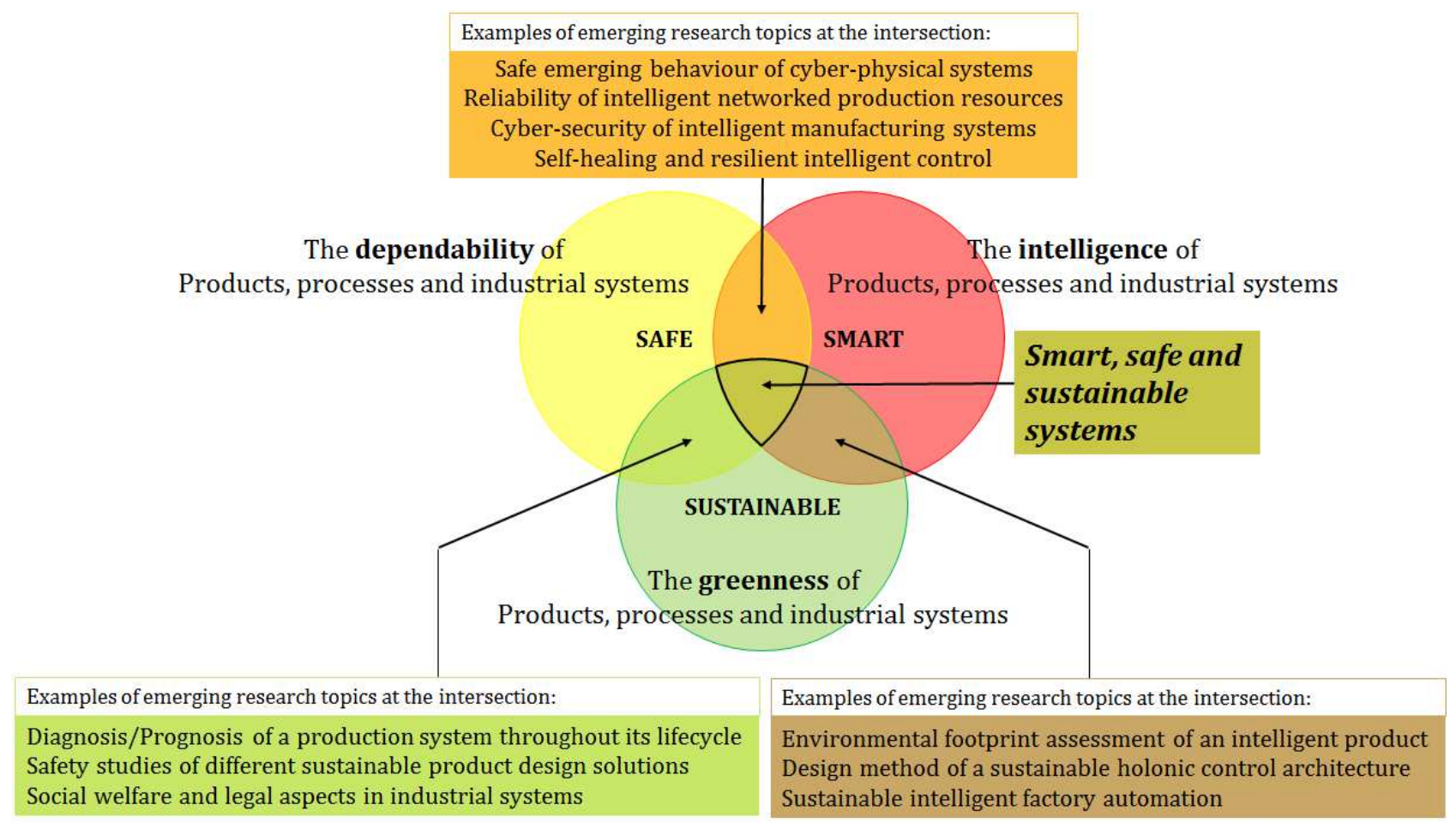

Fig. 1 The future of products, processes and industrial systems: the $3 \mathrm{~S}$ ' point of view.

"Safe" here is taken in the broad sense, referring for example to the reliability, availability, security, testability and maintainability dimensions of products, processes and industrial systems that are evaluated through dependability studies (Benard et al., 2008). This dimension aims at ensuring the correct functioning and the permanent safety of the three types of entities, in whichever lifecycle phase they evolve or are studied. Robustness and resilience are also relevant concepts when dealing with reaction and adaptation to perturbations during their use, whether localized or more global (Bergström et al., 2015). This vision is not new; it was initially designed for complex systems when designers were seeking to develop systems from a functional point of view, possibly including Integrated Logistics Support (ILS), and co-designed to ensure functional support of the complex system (Kriaa et al., 2015). We think it is crucial to consider safety as a whole and through this, to look at future products, processes and industrial systems with a global, functional view of their lifecycle. In such a context, it is worth mentioning that only a few studies have been carried out to ensure the safety and the dependability of future industrial systems characterized by the "bottom-up" approaches introduced (Sanislav et al., 2016). Some of the papers in this special issue address this dimension, thanks to which future industrial systems, products and processes will be predictable: They will be doing what they are designed to do in a safe way, they will perform safe production 
processes, and their interaction with humans will not be dangerous or will not result in hazardous decisions being made.

"Smart" represents the intelligent control dimension of products, processes and industrial systems; it refers to computing and service-oriented, intelligent solutions and means that will be engaged in the aforementioned products, processes and industrial systems. Future products and systems will be systematically connected: objects (products or resources) will communicate with each other to choreograph production as well as with people to improve the efficiency of the production and logistics systems, and the design process. For example, the German strategic initiative 'Industry 4.0' fosters the development of smart industrial systems using cyber-physical systems. As discussed in some of the articles in this special issue, the majority of recent research concerns improving production, transport/logistics (e.g., the physical internet) and supply chains performances. New controls based on advanced ICT convergence such as distributed control (Trentesaux, 2009), holonic organisation (Giret and Botti, 2009), multi-agent frameworks (Leitão et al., 2012), service orientation (Borangiu et al., 2012), virtualization and virtual commissioning (Berger et al., 2015), cloud manufacturing $(\mathrm{Xu}, 2012)$, cyber-physical systems (Lee et al., 2015), intelligent products (McFarlane et al., 2013) and Internet of Things (Atzori et al., 2010) will foster the development of innovative smart industrial solutions. In such a context, interoperability with existing information and decision systems, typically Manufacturing Execution Systems (MES) and Enterprise Resource Planning (ERP) is a key issue to ensure the viability of smart solutions for which the use of ontologies can be proposed (Alsafi and Vyatkin, 2010). To design optimized and reactive smart industrial solutions, the integration of optimization techniques from Operation Research, with learning models, simulation models or reactive technics is now widely addressed by researchers. Thanks to this dimension, future industrial systems, products and processes will be able to sense, communicate, and decide; they will be able to react, learn, adapt and evolve in the face of unexpected events.

"Sustainable" represents the greenness dimension of products, processes and industrial systems to maintain an equilibrium between economic, social and environmental requirements and constraints. The most frequently quoted definition of "Sustainable development" is from Our Common Future, also known as the Brundtland Report (United Nations, 1987): "Sustainable development is the development that meets the needs of the present without compromising the ability of future generations to meet their own needs". In 1993, Allenby and Graedel proposed the industrial ecology concept (Graedel and Allenby, 2002); (Ehrenfeld, 2004) introduced for the first time the concept of sustainable manufacturing and more recently (Garetti and Taisch, 2012) defined it as "the ability to smartly use natural resources for manufacturing, by creating products and solutions that, thanks to new technology, regulatory measures and coherent social behaviours, are able to satisfy economic, environmental and social objectives, thus preserving the environment, while continuing to improve the quality of human life". This dimension requires the adoption of a global view on the system's lifecycle (Product Lifecycle Management - PLM, lifecycle analysis and assessment, ...), (Zhang et al., 2015). Specifically, energy represents a promising field of research (Prabhu et al., 2015). Thanks to this dimension, future products, processes and industrial systems will feature the right balance between the three economic, environmental and social pillars of sustainable development; their footprint will be as minimal as possible and their potential benefits for society will be as high as possible, while enabling the economic growth of companies.

\section{Smart, Safe, Sustainable products, processes and industrial systems: positioning of the papers}

The ' $3 S$ ' must be considered simultaneously when describing usable and liveable future products, processes and industrial systems. The existing literature generally focuses on only one or sometimes two of the ' $\mathrm{S}$ ', but rarely on all three at the same time. In figure 1, some research topics at the intersection of two of the three dimensions have been presented, with the "holy grail" being in the centre of the picture. Furthermore, behind of each of these ' $S$ ' attributes exist powerful and rather 
closed research communities that do not pay enough attention to the other two. Some attempts have been made to change this and we provide below some illustrative ones:

- at the intersection of the "Safe" and "Sustainable" dimensions: these dimensions have some notions in common such as system lifecycle and maintenance as a key factor in reducing safety issues (Iung and Levrat, 2014).

- At the intersection of the "Safe" and "Smart" dimensions: these dimensions could be brought closer by studying the distribution of intelligence in heterarchical production control of which global behaviour, sometimes emerging, must be proven as safe and reliable with a sufficient degree of real-time availability (Sanislav et al., 2016).

- At the intersection of the "Smart" and "Sustainable" dimensions: the gap between these dimensions is historically high (Thomas et al., 2012). The "Sustainable" and "Smart" dimensions can be studied from the point of view of Intelligent Products (Främling et al., 2013). This dimension is being increasingly addressed to design future, usable (and liveable) industrial systems (Despeisse et al., 2012), (Giret et al., 2015).

This special issue attempts to reduce the gap between these three dimensions. The call for papers fostered submissions in line with the editorial policy of the Elsevier Journal Computers in Industry. It presents thus papers addressing at least the smart dimension, but that look at the other two dimensions, as shown in Table 1.

The next section provides a short description of the 13 papers composing this special issue.

Table 1. Coverage of the 3 'S' dimensions by the 13 articles published in this special issue.

\begin{tabular}{|c|c|c|c|}
\hline Article & Smart & Safe & Sustainable \\
\hline (Leitão et al., 2016) & $\mathbf{X}$ & & $\mathbf{X}$ \\
\hline (Morariu et al., 2016) & $\mathbf{X}$ & (x) & \\
\hline (Panescu and Pascal, 2016) & $\mathbf{X}$ & $(\mathrm{x})$ & \\
\hline (Cerri and Terzi, 2016) & $\mathbf{X}$ & & $\mathbf{X}$ \\
\hline (Negri et al., 2016) & $\mathbf{X}$ & $(\mathrm{x})$ & \\
\hline (Bayar et al., 2016) & (x) & $\mathbf{X}$ & (x) \\
\hline (Tang et al., 2016) & (x) & & $\mathbf{X}$ \\
\hline (Sallez et al., 2016) & $\mathbf{X}$ & & $\mathbf{X}$ \\
\hline (McFarlane et al., 2016) & $\mathbf{X}$ & & (x) \\
\hline (Giret et al., 2016) & $\mathbf{X}$ & $(\mathrm{x})$ & \\
\hline (Babiceanu and Seker, 2016) & $\mathbf{X}$ & (x) & \\
\hline (Walha et al., 2016) & $\mathbf{X}$ & & (x) \\
\hline (Dang et al., 2016) & $\mathbf{X}$ & & (x) \\
\hline
\end{tabular}

\section{Description of the papers composing this special issue}

As introduced earlier, Industry 4.0 is a German initiative focusing on industrial production that promotes the computerization of traditional industries, aimed at designing intelligent factories characterized by adaptability, efficiency, functionality, reliability, safety and usability, while striving to integrate customers and business partners in business processes and value chains. In this context, 
the paper entitled "Industrial Automation based on Cyber-Physical Systems Technologies: Prototype Implementations and Challenges" written by Paulo Leitão et al., addresses the topic of Cyberphysical systems (CPS) (Leitão et al., 2016). CPS constitute a suitable approach to achieve an Industry 4.0 and an Industrial Internet vision. CPS feature a tight combination of computational and physical elements to develop intelligent, dynamic, and self-* large-scale systems, covering inter- and intra-enterprise integration, and providing significant benefits in several emergent domains of application such as smart grids/buildings/transportation, and particularly in smart manufacturing. This paper introduces an integrated methodology to develop intelligent, dynamic and self-* largescale cyber-physical systems. It is based on the use of service-oriented multi-agent systems and comprises four main steps: 1) use of Multi-agent-Systems (MAS) to implement distributed intelligence; 2) combination of MAS with some complementary technologies to overcome some limitations of solutions implemented by MAS, namely interoperability in vertical and horizontal integration and integration with low level control; 3) consideration of insights from social and biological systems, which provide many simple but powerful mechanisms to handle complex environments; and 4) call for technology enablers to support the operation of ubiquitous CPS environments..

Virtualization of manufacturing execution system (vMES) workloads offers enterprises a set of design and operational advantages, the most visible being improved resource utilization and flexibility of the overall solution. The paper entitled "Redundancy and scalability for virtualized MES systems with Programmable Infrastructure" written by Octavian Morariu et al., explores redundancy and scalability, as well as other important operational advantages introduced through the use of private clouds for MES virtualization within the context of the programmable infrastructure (PI) concept (Morariu et al., 2016). PI is a new architectural approach in which the computing infrastructure, represented by resources, networks and storage, becomes dynamic and is controlled by the application, in contrast with traditional architectures where the application has to adapt to a static infrastructure. For MES applications, the adoption of PI has the potential to add a new layer of flexibility and optimization by allowing quick configuration and re-configuration in real time based on environmental changes, especially in the context of virtualization in a private cloud where workloads can be provisioned and de-provisioned in real time. In this context, this paper presents the main redundancy and scalability requirements for the workloads identified in ISA-95.03-based solutions and discusses in detail the strategies to assure the redundancy and scalability requirements of these workloads both individually and at solution level. A pilot implementation based on PI concepts is also presented. The experimental results show the system's response to a set of failure scenarios, focusing on the reconfiguration time of workloads and the dynamic response to increased load, showcasing the scalability of the solution.

The paper entitled "Holonic Coordination Obtained by Joining the Contract Net Protocol with constraint Satisfaction" written by Doru Panescu and Carlos Pascal, presents an additional step towards the application of Holonic Manufacturing Systems (HMS) by considering practical cases and addressing some important issues regarding holon coordination and validation in HMS (Panescu and Pascal, 2016). It shows how holarchies can be formed through a combination of Contract Net Protocol (CNP) and the Distributed Constraint Satisfaction Problem (DisCSP), and how certain properties of the solution obtained can be proved by using appropriate Petri net models. This research work takes into account holon classification and operation according to the HAPBA holonic architecture, which was developed from the PROSA reference architecture. The focus is on the shop-floor level of a company, and the scenarios considered refer to robotized processes, where robots must fill pallets with different types of parts. The job description includes specification of the types of parts and their final positions; constraints are unknown at global level, so it is almost impossible to apply a centralized approach. The first phase of the coordination scheme regards CNP. The manager composes a first-phase solution that minimizes the total cost and dispatches corresponding interim contracts. The second coordination stage then begins when the resource (robot) holons operate according to the DisCSP by applying the technological and environmental constraints in order to find 
a detailed solution. Thus, the combination CNP - DisCSP leads to an efficient mechanism. The decision regarding which holons must be included in the holarchy that solves the manufacturing goal is made in the first phase based on CNP. Then, the second phase determines detailed plans for resource holons according to all constraints. The authors conclude that the proposed coordination sequence leads to a good trade-off between complexity and optimality.

In recent years, companies have been forced to face many changes, particularly with the pressure of emerging low-cost countries which prevents them maintaining a price-based strategy. Environmental problems are considered more and more due to the strict regulations and standards imposed, like the Kyoto protocol or the tons of EU Directives. One way to ensure sustainability is to implement a product life cycle approach (US EPA, UNEP), which enables companies to assess the total cost and the total environmental impact. Since the 60s, methodologies to support the evaluation of the costs and environmental impacts generated throughout the whole product life cycle have been developed. In the light of all this, the aim of the paper entitled "Proposal of a Toolset for the Improvement of Industrial Systems' Life Cycle Sustainability through the Utilization of ICT Technologies" written by Daniele Cerri and Sergio Terzi, is to present a framework for the improvement of Industrial Systems' Life Cycle sustainability through the use of ICT (Cerri and Terzi, 2016). The framework is based on two tools: i) PLCO (Product Life Cycle Optimization), a tool to identify an optimal life cycle-oriented solution which defines the optimal composition of production line stations in order to minimize life cycle costs and life cycle environmental impacts; and ii) PLM Data Analysis, which has the potential to collect huge amounts of field data from the line stations and to process these data in order to return useful information for designers and system engineers. At practical level, PLM Data Analysis can collect data from files by importing csv files from workstation PLC or by using the new QLM (Quantum Lifecycle Management) language developed by The Open Group. This framework is then applied to a real case that simulates the system life cycle of an assembly line produced by a global company selling industrial systems (assembly or manufacturing lines), mainly in the automotive sector.

The paper entitled "Requirements and languages for the semantic representation of manufacturing systems" written by Elisa Negri et al., concerns the development of ontologies and ICT conceptual models allowing the formal and shared definition of the types, properties and interrelationships of entities for a particular domain of discourse, and the use of these representations in a variety of contexts (Negri et al., 2016). Ontologies are a way of representing knowledge related to a domain, and this knowledge can be represented within automated and software-based systems due to their formal nature. This paper presents two areas of contribution: 1) It proposes a study of the semantic languages and tools to support ontologies in the manufacturing domain that are available in the literature and commercially. ii) It shows a possible use of ontologies in the manufacturing domain to overcome some problems related to attaining greater flexibility and re-configurability of production systems. The first contribution results from a thorough literature review and analysis using an interdisciplinary approach covering the fields of industrial engineering, information technology, and industrial automation. The second contribution aims at illustrating the potentialities of the semantic addition of ontologies to the paradigm of open automation of manufacturing systems. This paradigm is meant to be an answer to the problems of control flexibility and re-configurability in production systems at software level, and is achieved by developing a distributed control structure based on smart components. Different solutions can be implemented to create a network of smart components (i.e. Cyber Physical System) using Profibus and Service Oriented Architectures; the latter is considered in this paper. The result of this second contribution is an industrial example that demonstrates the relevance and industrial applicability of the concepts introduced above. In particular, the paper presents the ontological modelling of a real industrial logistics system (a picking system) and envisions the possible exploitation of this ontology at control level in the specified industrial context.

Production systems are subject to several types of disruptions. Such events lead to detrimental consequences, including direct impacts and probable downstream effects, usually called production 
system risks. Disruptions and risks may break the continuity of workflows, disturb pre-set organization processes, and prevent the production system from reaching its expected levels of performance. The main objective of the paper entitled "Using immune designed ontologies to monitor disruptions in manufacturing systems" written by Nawel Bayar et al., is related to the on line detection of disruptions and the study of their consequences enabling quick reaction and guided decisionmaking (Bayar et al., 2016). Recently, biological immunity inspired the design of promising integrated and generic frameworks to manage disruptions and risks in manufacturing systems. However, these studies focused on designing the general conceptual framework and suggesting methodological guidelines to apply immune concepts and mechanisms to solve manufacturing problems. They did not focus on showing the detailed design of immune-type ontologies, demonstrating their usage in detecting disturbances, identifying risks and suggesting control decisions, or discussing their integration and compliance with existing industrial information systems and business process legacy software. In this paper, the authors provide the detailed design of an immune-based ontology and show how to use it as a tool to detect disruptions, identify risky consequences and propose reaction decisions in manufacturing systems. They consider a case study from the steel industry, and the proposed tool contributes to design-integrated and reactive knowledge-based approaches for disruption and risk management, allowing software agents and legacy systems to share and reuse knowledge about disruptions and risks in manufacturing systems.

Due to increasing energy requirements and associated environmental impacts, manufacturing companies are now facing new challenges to meet rising demands in sustainability. Most existing research on reducing energy consumption in production scheduling problems focuses on static scheduling models. However, many unexpected disruptions exist in a real-world production system such as new job arrivals and machine breakdowns. In the paper entitled "Energy-efficient dynamic scheduling for a flexible flow shop using an improved particle swarm optimization" written by Dunbing Tang et al., the authors propose an approach to address the dynamic scheduling problem with reduced energy consumption and increased makespan for flexible flow shop scheduling (Tang et al., 2016). Firstly, a mathematical model for minimizing makespan and energy consumption is defined to specify the dynamic scheduling problem. Secondly, since the problem is strongly NP hard, a novel algorithm based on improved particle swarm optimization, inspired from a hormone modulation mechanism, is adopted to search for an optimized solution of the bi-objective model. Finally, the numerical results from the experiments are reported to evaluate the performance and efficiency of the proposed approach.

In the paper entitled "On the Activeness of Intelligent Physical Internet Containers" written by Yves Sallez et al., the stakes and challenges of Internet of Things highlight that a more distributed real time approach will contribute to supporting a more efficient organization (Sallez et al., 2016). In the PI (Physical Internet) concept, goods are encapsulated in modularly sized, reusable or recyclable smart containers, called PI-containers. The first part of the paper presents the physical and informational requirements, as well as key functional specifications to fulfil logistics needs. The second part presents the state of the art in the field of PI-containers and "smart" PI-containers. The notion of PI-container activeness is described in the third part. In the context of PI, communication, memory and processing capabilities can be associated with the PI-container to make it active so as to support the previously introduced informational requirements. With such capabilities, the container can identify its state and report it, compare its state with the desired one, and send information (e.g. warnings) when certain conditions are met. The fourth part of the paper focuses on applicative examples of the previous analysis framework. Several applications (basic traceability, monitoring of perishable freight and reactive routing in a PI-hub) are successively presented and analysed.

Modern logistics is becoming increasingly challenging with the need to directly support interactions with the end customer rather than the retailer. The customer, especially in e-commerce, seeks the spontaneity and immediateness of "High Street" shopping with the range, pricing, and convenience of remote purchasing via the internet or by telephone. The paper entitled "Intelligent 
Logistics: Involving the Customer" written by Duncan McFarlane et al. studies the ways in which the logistics customer can get "closer" to his/her order via automated software describing his/her needs and preferences to the logistics provider dealing with his/her order (McFarlane et al., 2016). In this way, changing customer preferences such as order customization, changing delivery details or priorities will automatically be conveyed to the warehouse and the management of the order amended - potentially during the execution of the order. The authors argue that in the extensive field of intelligent logistics, a smart customer-oriented solution could be attractive in some circumstances and that it may be conveniently implemented using the intelligent product model. This is done through both a high level definition and a series of possible industrial scenarios. A review of recent work in developing a game theoretic framework for qualitatively assessing benefits for providers and customers from customer-oriented logistics offerings is also presented. The benefit analysis demonstrates the conditions under which the provider and/or customer will benefit from customeroriented logistics in terms of cost selection, delivery requirements, and the nature of the logistics operations. The authors also examine the questions of how to develop and deploy customer-oriented logistics and how the provider can prepare and manage his operations most effectively to allow more customer interventions during order execution. Finally, the authors investigate the challenges of deploying intelligent product-based systems in environments where there is an operational Warehouse Management System, and discuss the potential changes and extensions required.

Service Oriented Manufacturing Systems (SoMS) are currently emerging to help with the implementation of enterprise business partnership networks in which each participant provides others with specialized services. However, these systems are complex and hard to engineer. The main source of complexity is the number of different technologies, standards, functions, protocols, and execution environments that must be integrated in order to produce them. The paper entitled "An Engineering Framework for Service-Oriented Intelligent Manufacturing Systems" written by Adriana Giret et al. proposes a framework and associated engineering approach to assist Service-Oriented Manufacturing System developers (Giret et al., 2016). The approach combines Multi-agent Systems with ServiceOriented Architectures for the functional development of intelligent automation control and execution of manufacturing systems.

The paper entitled "Big Data and Virtualization for Manufacturing Cyber-Physical Systems: A Survey of the Current Status and Future Outlook" written by Radu F. Babiceanu and Remzi Seker, highlights how advances in sensor and communication technologies can provide the foundations for linking the physical facility and machine world to the cyber world of Internet applications and the software world (Babiceanu and Seker, 2016). A sensor-packed manufacturing system, in which each process or piece of equipment providing events and status information, coupled with market research for true advanced Big Data analytics, seem to provide the right ingredients for event response selection and operation virtualization, thus moving manufacturing operations closer to the cloud manufacturing paradigm. This work provides a comprehensive literature review of the current status of virtualization and cloud-based services for manufacturing systems, and the use of Big Data analytics for manufacturing operation planning and control. The authors propose a framework for the development of manufacturing cyber-physical systems that include capabilities for connecting to the Internet of Things, and for complex event processing and Big Data algorithmic analytics.

In the paper entitled "A rail-road PI-hub allocation problem, active and reactive approaches" written by $F$. Walha et al., the authors looked at the promising Physical Internet (PI) paradigm, focusing on PI crossdocking systems named "rail-road $\pi$-hub" (Walha et al, 2016). They studied the optimization of the distance travelled by each container to docks and the number of trucks used. To achieve this, heuristic, metaheuristic and multi-agent-based approaches are proposed. With a given sequence of all containers in the train, the proposed heuristic approach can assign these containers to outbound doors. A Simulating Annealing (SA) method improves this allocation by minimizing the distance travelled. A multi-agent system model is also proposed to generate reactive solutions which take dynamic aspects into account. The experimental results show that the proposed SA allows an 
improvement of about 2.42 to $7.67 \%$ in comparison with the solution generated by the heuristic; it provides robust results within a reasonable time. Additionally, the multi-agent-based approach provides good solutions in case of perturbations or unexpected events.

In the paper entitled "Electromagnetic Modular Smart Surface Architecture and Control in a Microfactory Context" written by Dang et al., an electromagnetic conveyance system called electromagnetic modular Smart Surface (emSS) is presented. It enables pallets to be moved on a planar surface in a microfactory context (Dang et al., 2016). The objective of this system is to reconfigure the production system layout as flexibly as possible according to routing files. A framework is defined to monitor and control the emSS by simulation or in-line, and to minimize human interventions by changing product routing when emSS component failures occur. Experiments were conducted on an emSS prototype, allowing the comparison of two strategies regarding cost function linked to energy consumption and velocities.

\section{Perspectives of future research in the ' $3 \mathrm{~S}$ ' dimension}

As expressed above, there is a clear lack of convergent, well-balanced R\&D activities between the smart, safe and sustainable dimensions to obtain fully usable and liveable systems. In this chapter, we discuss some new lines of research that will use emergent information and communication technologies for the convergence of the ' $3 \mathrm{~S}$ '.

\subsection{Future research in the "Safe" dimension to integrate the ' $3 S$ '}

Most of existing research relative to this topic concerns the food distribution channel (Akkerman et al., 2010) or urban life (Raco, 2007) and, as previously introduced, big or complex integrated systems (energy plant for example). From our point of view, the "safe" dimension is not sufficiently studied, especially by researchers working on smart ICT and systems (cf. figure 1). As a clear example of this shortcoming, we consider the following example: Let a swarm of embedded systems, integrated into large CPS. These CPS are composed of Intelligent Products, smart machines, and resources, for example. This is currently a widespread approach used to design future industrial systems. However, there are currently no contributions along with dependability studies, which clearly forbids any real full-scale implementation of the proposed solution.

One reason comes from the fact that these embedded systems are small (e.g., electronic cards attached for a resource of a product), compared to the complex systems initially addressed by safety designers (train, plane, nuclear plant...) (Zamojski et al., 2012). For each of these "small" systems, researchers consider that either the safety studies are out of scope or their nonexistence is not so risky, but they are making a fundamental mistake. The huge number of these "small" systems will generate a non-negligible risk for global safety because of unexpected emerging behaviours or because of the conditional global probability of failure that increases rapidly for a large set of small, nearly-perfect, interacting "small" components.

Another reason comes from the fact that when developing future products, processes and industrial systems, researchers deal mainly with physical and informational flow management. They seldom collaborate with researchers working on dependability and risk management. Typically, they do not ask themselves questions such as "What if some smart components fail?", "Is it possible for my system to generate hazardous command signals?", "Did I consider possible external threats?", "Has my system been designed in conjunction with interactions with human operators?" (Trentesaux and Millot, 2016).

A third reason comes from the fact that most research aimed at designing embedded systems (and CPS) in industry is currently seeking to reach the "proof-of-concept" stage and not the final "industrialization" stage for which such studies are compulsory. 
From our point of view, this issue must obviously be resolved and there are a huge number of ways to address the safe dimension of future products, processes and industrial systems. For example, a first research activity would bring together researchers in dependability/safety and researchers in smart systems, e.g., (Cauffriez et al., 2016). For years, researchers in safety and dependability having been putting some effort into studying interconnected/communicating systems, assuming that a network with limited reliability is used (Zhu, 2012). This is clearly interesting for researchers working on smart industrial systems, but these studies do not consider the full functional expectations for smart systems with regard to their ability to react, adapt, reconfigure, re-organize and self-organize themselves (Le Mortellec et al., 2013). This is thus a new innovative field of research for the former researchers while the latter should benefit from deploying smart systems with proven dependability and safety levels.

A second promising research activity should deal with how potential benefits from down-streaming and up-streaming information across the lifecycle phases of smart products and industrial systems would increase the reliability and availability of such systems (Sallez et al., 2010). For example, during manufacturing, safety mainly concerns the industrial system's maintainability through predictive and/or proactive maintenance while another new line concerns prognostics and health management of smart systems. According to this paradigm, the idea is to generate a prognosis related to resources, or more generally to the shop-floor based on stochastic algorithms. Thus, the PHM (Prognostics and Health Management) concept extends the idea of predictive maintenance thanks to the optimization of maintenance and logistic support to improve availability and reduce costs (Scanff et al., 2007). The most important way to achieve this is to capture in real time, information from the sensors and all follow-up appliances providing information about the shop-floor state (resources, material flow and environment) (Dumitrache and Borangiu, 2012), (Borangiu et al., 2015a). Availability and reliability will be optimized throughout the lifecycle through successive upgrades, or being redesigned or overhauled.

\subsection{Future research in the "Sustainable" dimension to integrate the ' $3 S$ '}

The sustainable dimension is also rarely addressed when working on future products, processes and industrial systems. Despite some efforts at high levels (typically supply chain level) or at technical level (e.g., "green" technologies), intermediary levels that typically deal with intelligent and smart planning, scheduling and control, are still not addressed from a sustainability perspective (Giret et al., 2015). Until now, the most studied field relevant to sustainability at this level is energy (Prabhu et al., 2015), (Raileanu et al., 2015). The question is how smart entities, intelligent products or future industrial systems can provide new solutions to achieve "green" functioning or liveable industrial conditions.

It has been highlighted how smart industrial and logistics systems can improve the efficiency of the industrial system considered, by enhancing reactivity, decision making, inventory management and so on (Thomas and Trentesaux, 2014). In this sense, such intelligent systems are already sustainable because they lead to better economic conditions increasing system resilience and thus sustainability (Prabhu, 2012), (Prabhu et al., 2013), (Raileanu et al., 2015). Product-carried information leads to economic improvement, as previously introduced, saving time in operational management, saving resource capacities in scheduling (Herrera et al., 2012) or saving energy in implementation (Pach et al., 2015). Moreover, some intelligent and smart industrial applications were implemented that sought to reproduce animal behaviour using biomimetic control approaches (Karnouskos et al., 2009). Concerning energy savings, for example, opportunistic energy management at shop floor level may be naturally addressed using smart intelligent distributed devices (Trentesaux and Giret, 2015). A typical illustration of this approach is proposed by (Karnouskos et al., 2009). Lately, the emerging concept of the Physical Internet is also an emanation of these smart industrial and logistics systems (Montreuil, 2011). 
In addition, some recent research concerns product and material recyclability (Derigent and Thomas, 2016), but no work relevant to processes recyclability was found. The main subject of existing articles concerns reverse logistics management (Linton et al., 2007), as well as how to select which components have to be recycled, but not how to manage their recycling process. Recently, Graedel and Allenby expressed the problem of industrial ecology and sustainable engineering (Graedel and Allenby, 2010). In their article, (Dunn and Steinemann, 1998) analyse the Kalundborg eco-industrial system in Denmark to highlight how this concept can ensure implementation of the key sustainability principles. Van Gorp (van Gorp, 2007) analyses the ways in which designers deal with ethical considerations, taking into account safety and sustainability in engineering design processes. But finally, and to the best of our knowledge, few studies have been conducted on process durability concepts. Moreover, no work dealing with ways of addressing the third pillar (social), or all three together, with ICT and smart solutions, was found. It seems obvious that on-line information, realtime communication, dynamic data storage and so on, will be arguments for using ICT in technical, industrial and human systems. In addition, the field of investigation and the prospects are very extensive: energy and material reduction, system durability, cost control, employability, and so on. One of the interests of taking into account the three sustainable pillars thanks to ICT is the low cost of information gathering, activity follow-up and traceability, reporting... that are still obstacles in such sustainable projects. That is why new research must address these concepts in order to develop an increasingly sustainable industrial world.

\subsection{Future research in the "Smart" dimension to integrate the ' $3 S$ '}

In this special issue, the smart dimension is logically the most frequently addressed among the ' $3 \mathrm{~S}$ '. It has a big impact on the other two, Safe and Sustainable, for which it provides permanent development support through constantly changing technological solutions. There are numerous future lines of research in the "Smart" direction integrating the ' $3 \mathrm{~S}$ ', mainly due to the ambitious performance objectives of dependability, performance and greenness that converge through the ' $3 \mathrm{~S}$ ' leading to the digital transformation of manufacturing. In this section, we describe some of the most challenging potential lines of research.

From our perspective, research in the "Smart" dimension will accelerate the digital transformation of manufacturing through:

1. Instrumentation of manufacturing resources (machines, robots, AGVs, storage, product carriers, buffers, etc.) and environment (workplaces, material flow, transport, access points, etc.) allowing product routing and traceability, production tracking, evaluation of resource status and quality of services, etc.

2. Interconnection of orders, products / components / materials, resources in a service-oriented approach using multiple communication technologies: wireless, broadband Internet, mobile applications (Morel et al., 2003).

3. Intelligent, distributed production control via:

- New controls based on ICT convergence in automation, robotics, vision, multi-agent control and holonic organization, which makes the smart factory possible.

- New operations based on product and process modelling and simulation. Ontologies that are becoming "common vocabulary" to provide semantic descriptions/abstract models of the manufacturing domain: core ontology - modelling of assembly processes (resources, jobs, dependencies, etc.); scene ontology - modelling product flow; events ontology - modelling various expected/unexpected events and disruptions. These models and knowledge representation make the digital factory possible (Borangiu et al., 2009), (Raileanu et al., 2014).

- Novel management of complex manufacturing value chains (production, supply, sales, delivery, after-sale services) for the networked virtual factory a) across manufacturing sites: logistics, material flows, and b) across the product lifecycle. 
There are "Smart" control solutions, architectures and applications developed which rely on:

1. Distributed Intelligent Control at Manufacturing Execution System (MES) and shop floor levels based on ICT frameworks: distributed control across autonomous intelligent units (agents), multi-agent systems (MAS), holonic organizations and product-driven automation.

2. Service Oriented Architectures (SOA), increasingly used as implementation means for MAS. Business and process information systems integration and interoperability at enterprise level will require the customized product to be "active controller" of the enterprise resources, thus providing consistency between the material and informational flows. Service orientation in the manufacturing domain is not limited to just web services, but will transpose the choreography and orchestration concepts from the information technology realm to the shop floor process area.

3. Manufacturing Service Bus (MSB 2.0) integration model: an adaptation of Enterprise Service Bus (ESB) technology for manufacturing enterprises; it introduces the principle of bus communication between the manufacturing layers acting an intermediary for data flows and ensuring loose coupling of manufacturing modules (Morariu, 2013).

Holonic Manufacturing Systems (HMS) (Valckenaers and Van Brussel, 2005) and SOA are currently two of the most studied and referenced solutions for the next generation of smart manufacturing control systems. Both of these solutions provide the necessary guidelines to create open, flexible and agile control environments for smart, digital and networked factories. The combination of both paradigms appears to be a very attractive solution for the new generation of MES thanks to the flexibility provided by (a) HMS at a structural level in the control architecture, and (b) SOA at process level, with the decomposition and encapsulation of manufacturing processes allowing their distribution among resources.

The holonic approach is the main engine for the digital transformation of manufacturing at MES middle layer and shop-floor production control layer level regarding "Distribution" and "Intelligence". The Holonic manufacturing paradigm is based on defining a main set of assets: resources (technology, humans - reflecting the producer's profile, capabilities, skills), orders (reflecting the business solutions), and products (reflecting the client's needs, value propositions) represented by holons communicating and collaborating in holarchies to reach a common goal expressed by orders (Borangiu et al., 2013), (Novas et al., 2012). Due to the fact that:

$$
[\text { Holon }] \leftarrow[\text { Physical Asset }]+[\text { Agent }=\text { Information counterpart }]
$$

it becomes possible to solve all specific activities of physical manufacturing (batch planning, product scheduling, resource allocation, inventory update, product routing, execution, packaging, tracking and quality control) i) triggered by real-time events gathered from the manufacturing structure processes and devices, and ii) controlled in real time, with orchestration and choreography assured by SOA in standard secure mode at informational level. Thus, the holarchy created by the holons defined for any HMS acts as a Physical Multi-Agent System (PMAS), or a CPS, transposing the inherent distribution induced by an agent implementation framework to the physical realm according to defined manufacturing ontologies.

Cloud manufacturing (CMfg) and MES virtualization will be introduced in future "Smart" developments as a networked and service-oriented manufacturing model focusing on new opportunities in the field of networked manufacturing (NM), as enabled by the emergence of cloud computing platforms. The cloud-based service delivery model for the manufacturing industry includes product design, batch planning, product scheduling, real-time manufacturing control, testing, management and all other stages of a product life cycle (Morariu et al., 2013a), (Morariu et al., 2014), (Morariu et al., 2015).

Another important research area concerns the study of resource virtualization techniques and resource sharing in manufacturing environments. An innovative model, recently proposed for 
resource sharing in grid manufacturing, is composed of several layers: a network infrastructure layer, a manufacturing resource aggregation layer, a manufacturing resource management layer, a manufacturing service application layer and a portal layer. It is currently agreed that resource and resource capability virtualization and modelling represent the starting point for encapsulating manufacturing services in the cloud (Wang and $\mathrm{Xu}, 2013$ ).

The cloud adoption strategy results in an architecture that is robust enough to ensure the information flow is in sync with the material flow at all times (Colombo et al., 2014), and at the same time flexible enough to allow dynamic reconfiguration and SOA governance(Babiceanu and Chen, 2006), (Borangiu et al., 2009). Standard alignment is also an important factor to consider for interoperability and reuse.

In this context, MES virtualization involves migration of all MES workloads, traditionally executed on physical machines, to the data centre, and more specifically to the private cloud infrastructure as virtual workloads. The idea is to run all the control software in a virtualized environment and only keep the physical resources with their dedicated real time controllers on the shop floor. This separation between hardware resources and software that controls them provides a new level of flexibility and agility for the manufacturing solution (Wu and Yang, 2010), (Wang et al., 2012), (Cheng et al., 2010).

The concept of Intelligent Products (IP) (McFarlane et al., 2013), (Meyer et al., 2009) will be exploited in future research in the domain of "Smart items". The characteristics of the intelligent product and the fundamental ideas behind it can also be found in other emerging "Smart" technological topics, such as smart objects, objects in autonomous logistics and the Internet of Things. Circumstances have been identified (Morariu et al., 2013b) under which product intelligence as a paradigm for designing an information management environment might prove to be superior to a more conventional approach to managing the movement of a product as part of the logistical planning system of an organization. In manufacturing, the Intelligent Product is the driver for heterarchical operations scheduling and resource allocation, as well as product-driven automation (Leitão et al., 2015), (Främling et al., 2013).

To conclude this outlook relating to the "smart" dimension of future products, processes and industrial systems, challenges concerning the "Smart" dimension such as predicting unexpected, realtime resource team reconfiguration for the agility or virtualization of production workloads, address many production systems. Beyond product intelligence, over the next few years, bio-inspired paradigms will be also proposed, and developments in Internet, multi-agent software, flexible logic controllers, radio frequency tagging, and real time data management will help provide a platform for developing these solutions.

\section{Conclusion}

Considerable research efforts have been put into designing smart systems by themselves, but too little attention has been paid to the development of "smart and safe" systems as well as to the development of "smart and sustainable" systems, and almost no attention at all has been paid to the development of "smart, safe and sustainable" systems. As a clear illustration of this, the 13 articles in this special issue addressed one or two dimensions, but not actually the ' $3 S$ ' simultaneously. As emerging ICT concepts are increasingly understood and used, the guest editors of this special issue stress the necessity for researchers to intensify their research efforts to enable the convergence of the ' $3 \mathrm{~S}$ ', which is a basic requirement to design usable and liveable products, processes and industrial systems. From our point of view, to be usable and liveable, these future systems will need to be simultaneously safe, smart and sustainable. 
The guest editors of this special issue would like to thank the authors for their contributions, and the reviewers for their very professional and constructive reviews. The guest editors would also like to give special thanks to Nick Szirbik, the Special Issues Editorial Manager, for his reactive support throughout the process that led to the publication of this special issue.

\section{List of the articles composing the special issue}

Babiceanu, R.F., Seker, R., 2016. Big Data and virtualization for manufacturing cyber-physical systems: A survey of the current status and future outlook. Computers in Industry. doi:10.1016/j.compind.2016.02.004

Bayar, N., Darmoul, S., Hajri-Gabouj, S., Pierreval, H., 2016. Using immune designed ontologies to monitor disruptions in manufacturing systems. Computers in Industry. doi:10.1016/j.compind.2015.09.004

Cerri, D., Terzi, S., 2016. Proposal of a toolset for the improvement of industrial systems' lifecycle sustainability through the utilization of ICT technologies. Computers in Industry. doi:10.1016/j.compind.2015.09.003

Dang, T.A.T., Bosch-Mauchand, M., Arora, N., Prelle, C., Daaboul, J., 2016. Electromagnetic modular Smart Surface architecture and control in a microfactory context. Computers in Industry. doi:10.1016/j.compind.2016.02.003

Giret, A., Garcia, E., Botti, V., 2016. An engineering framework for Service-Oriented Intelligent Manufacturing Systems. Computers in Industry. doi:10.1016/j.compind.2016.02.002

Leitão, P., Colombo, A.W., Karnouskos, S., 2016. Industrial automation based on cyber-physical systems technologies: Prototype implementations and challenges. Computers in Industry. doi:10.1016/j.compind.2015.08.004

McFarlane, D., Giannikas, V., Lu, W., 2016. Intelligent logistics: Involving the customer. Computers in Industry. doi:10.1016/j.compind.2015.10.002

Morariu, O., Borangiu, T., Raileanu, S., Morariu, C., 2016. Redundancy and scalability for virtualized MES systems with programmable infrastructure. Computers in Industry. doi:10.1016/j.compind.2015.08.011

Negri, E., Fumagalli, L., Garetti, M., Tanca, L., 2016. Requirements and languages for the semantic representation of manufacturing systems. Computers in Industry. doi:10.1016/j.compind.2015.10.009

Panescu, D., Pascal, C., 2016. Holonic coordination obtained by joining the contract net protocol with constraint satisfaction. Computers in Industry. doi:10.1016/j.compind.2015.08.010

Sallez, Y., Pan, S., Montreuil, B., Berger, T., Ballot, E., 2016. On the activeness of intelligent Physical Internet containers. Computers in Industry. doi:10.1016/j.compind.2015.12.006

Tang, D., Dai, M., Salido, M.A., Giret, A., 2016. Energy-efficient dynamic scheduling for a flexible flow shop using an improved particle swarm optimization. Computers in Industry. doi:10.1016/j.compind.2015.10.001

Faiza WALHA, Abdelghani BEKRAR, Sondes CHAABANE, Taicir LOUKIL, A rail-road PI-hub allocation problem, active and reactive approaches

\section{References}

Akkerman, R., Farahani, P., Grunow, M., 2010. Quality, safety and sustainability in food distribution: a review of quantitative operations management approaches and challenges. OR Spectrum 32, 863904. doi:10.1007/s00291-010-0223-2

Alsafi, Y., Vyatkin, V., 2010. Ontology-based reconfiguration agent for intelligent mechatronic systems in flexible manufacturing. Robotics and Computer-Integrated Manufacturing 26, 381-391. doi:10.1016/j.rcim.2009.12.001

Atzori, L., lera, A., Morabito, G., 2010. The internet of things: A survey. Computer Networks 54, 2787-2805.

Babiceanu, R., Chen, F., 2006. Development and Applications of Holonic Manufacturing Systems: A Survey. Journal of Intelligent Manufacturing 17, 111-131. doi:10.1007/s10845-005-5516-y

Babiceanu, R.F., Seker, R., 2016. Big Data and virtualization for manufacturing cyber-physical systems: A survey of the current status and future outlook. Computers in Industry. doi:10.1016/j.compind.2016.02.004 
Bayar, N., Darmoul, S., Hajri-Gabouj, S., Pierreval, H., 2016. Using immune designed ontologies to monitor disruptions in manufacturing systems. Computers in Industry. doi:10.1016/j.compind.2015.09.004

Benard, V., Cauffriez, L., Renaux, D., 2008. The Safe-SADT method for aiding designers to choose and improve dependable architectures for complex automated systems. Reliability Engineering \& System Safety 93, 179-196. doi:10.1016/j.ress.2006.12.020

Berger, T., Deneux, D., Bonte, T., Cocquebert, E., Trentesaux, D., 2015. Arezzo-flexible manufacturing system: A generic flexible manufacturing system shop floor emulator approach for high-level control virtual commissioning. Concurrent Engineering 23, 333-342. doi:10.1177/1063293X15591609

Bergström, J., van Winsen, R., Henriqson, E., 2015. On the rationale of resilience in the domain of safety: A literature review. Reliability Engineering \& System Safety, Special Issue on Resilience Engineering 141, 131-141. doi:10.1016/j.ress.2015.03.008

Borangiu, T., Gilbert, P., Ivanescu, N.-A., Rosu, A., 2009. An implementing framework for holonic manufacturing control with multiple robot-vision stations. Engineering Applications of Artificial Intelligence 22, 505-521. doi:10.1016/j.engappai.2009.03.001

Borangiu, T., Răileanu, S., Berger, T., Trentesaux, D., 2015a. Switching mode control strategy in manufacturing execution systems. International Journal of Production Research 53, 1950-1963. doi:10.1080/00207543.2014.935825

Borangiu, T., Raileanu, S., Trentesaux, D., Berger, T., lacob, I., 2013. Distributed manufacturing control with extended CNP interaction of intelligent products. Journal of Intelligent Manufacturing 25, 10651075. doi:10.1007/s10845-013-0740-3

Borangiu, T., Thomas, A., Trentesaux, D. (Eds.), 2015b. Service Orientation in Holonic and Multi-agent Manufacturing, Studies in Computational Intelligence. Springer International Publishing, Cham.

Borangiu, T., Thomas, A., Trentesaux, D. (Eds.), 2012. Service Orientation in Holonic and Multi-Agent Manufacturing Control, Studies in Computational Intelligence. Springer.

Cauffriez, L., Grondel, S., Loslever, P., Aubrun, C., 2016. Bond Graph modeling for fault detection and isolation of a train door mechatronic system. Control Engineering Practice. doi:10.1016/j.conengprac.2015.12.019

Cerri, D., Terzi, S., 2016. Proposal of a toolset for the improvement of industrial systems' lifecycle sustainability through the utilization of ICT technologies. Computers in Industry. doi:10.1016/j.compind.2015.09.003

Cheng, Y., Tao, F., Zhang, L., Zhang, X., Xi, G.H., Zhao, D., 2010. Study on the utility model and utility equilibrium of resource service transaction in cloud manufacturing, in: 2010 IEEE International Conference on Industrial Engineering and Engineering Management (IEEM). Presented at the 2010 IEEE International Conference on Industrial Engineering and Engineering Management (IEEM), pp. 2298-2302. doi:10.1109/IEEM.2010.5674163

Colombo, A.W., Bangemann, T., Karnouskos, S., Delsing, J., Stluka, P., Harrison, R., Jammes, F., Lastra, J.L. (Eds.), 2014. Industrial Cloud-Based Cyber-Physical Systems. Springer International Publishing, Cham.

Dang, T.A.T., Bosch-Mauchand, M., Arora, N., Prelle, C., Daaboul, J., 2016. Electromagnetic modular Smart Surface architecture and control in a microfactory context. Computers in Industry. doi:10.1016/j.compind.2016.02.003

Derigent, W., Thomas, A., 2016. End-of-Life information sharing for a circular economy: existing literature and research opportunities, in: Service Orientation in Holonic and Multi-Agent Manufacturing Control. Springer.

Despeisse, M., Mbaye, F., Ball, P.D., Levers, A., 2012. The emergence of sustainable manufacturing practices. Production Planning \& Control 23, 354-376. doi:10.1080/09537287.2011.555425

Dumitrache, A., Borangiu, T., 2012. IMS10-image-based milling toolpaths with tool engagement control for complex geometry. Engineering Applications of Artificial Intelligence 25, 1161-1172. doi:10.1016/j.engappai.2011.09.026

Dunn, B.C., Steinemann, A., 1998. Industrial Ecology for Sustainable Communities. Journal of Environmental Planning and Management 41,661-672. doi:10.1080/09640569811353

Ehrenfeld, J.R., 2004. Can Industrial Ecology be the "Science of Sustainability"? Journal of Industrial Ecology 8, 1-3. doi:10.1162/1088198041269364 
Främling, K., Holmström, J., Loukkola, J., Nyman, J., Kaustell, A., 2013. Sustainable PLM through Intelligent Products. Engineering Applications of Artificial Intelligence 26, 789-799. doi:10.1016/j.engappai.2012.08.012

Garetti, M., Taisch, M., 2012. Sustainable manufacturing: trends and research challenges. Production Planning \& Control 23, 83-104. doi:10.1080/09537287.2011.591619

Giret, A., Botti, V., 2009. Engineering Holonic Manufacturing Systems. Computers in Industry 60, 428-440. doi:10.1016/j.compind.2009.02.007

Giret, A., Garcia, E., Botti, V., 2016. An engineering framework for Service-Oriented Intelligent Manufacturing Systems. Computers in Industry. doi:10.1016/j.compind.2016.02.002

Giret, A., Trentesaux, D., Prabhu, V., 2015. Sustainability in manufacturing operations scheduling: A state of the art review. Journal of Manufacturing Systems. doi:10.1016/j.jmsy.2015.08.002

Graedel, T.E., Allenby, B.R., 2010. Industrial ecology and sustainable engineering. Prentice Hall, Upper Saddle River, NJ.

Graedel, T.E., Allenby, B.R., 2002. Industrial Ecology. Prentice Hall.

Herrera, C., Berraf, S.B., Thomas, A., 2012. Viable System Model Approach for Holonic Product Driven Manufacturing Systems, in: Borangiu, T., Thomas, A., Trentesaux, D. (Eds.), Service Orientation in Holonic and Multi-Agent Manufacturing Control. Springer-Verlag Berlin, Berlin, pp. 169-181.

lung, B., Levrat, E., 2014. Advanced Maintenance Services for Promoting Sustainability. Procedia CIRP, Proceedings of the 3rd International Conference in Through-life Engineering Services 22, 15-22. doi:10.1016/j.procir.2014.07.018

Karnouskos, S., Colombo, A.W., Lastra, J.L.M., Popescu, C., 2009. Towards the energy efficient future factory. Presented at the Industrial Informatics, 2009. INDIN 2009. 7th IEEE International Conference on, IEEE, pp. 367-371. doi:10.1109/INDIN.2009.5195832

Kriaa, S., Pietre-Cambacedes, L., Bouissou, M., Halgand, Y., 2015. A survey of approaches combining safety and security for industrial control systems. Reliability Engineering \& System Safety 139, 156-178. doi:10.1016/j.ress.2015.02.008

Lee, J., Bagheri, B., Kao, H.-A., 2015. A Cyber-Physical Systems architecture for Industry 4.0-based manufacturing systems. Manufacturing Letters 3, 18-23. doi:10.1016/j.mfglet.2014.12.001

Leitão, P., Barbosa, J., Trentesaux, D., 2012. Bio-inspired multi-agent systems for reconfigurable manufacturing systems. Engineering Applications of Artificial Intelligence 25, 934-944. doi:10.1016/j.engappai.2011.09.025

Leitão, P., Colombo, A.W., Karnouskos, S., 2016. Industrial automation based on cyber-physical systems technologies: Prototype implementations and challenges. Computers in Industry. doi:10.1016/j.compind.2015.08.004

Leitão, P., Rodrigues, N., Barbosa, J., Turrin, C., Pagani, A., 2015. Intelligent products: The grace experience. Control Engineering Practice 42, 95-105. doi:10.1016/j.conengprac.2015.05.001

Le Mortellec, A., Clarhaut, J., Sallez, Y., Berger, T., Trentesaux, D., 2013. Embedded holonic fault diagnosis of complex transportation systems. Engineering Applications of Artificial Intelligence 26, 227-240. doi:10.1016/j.engappai.2012.09.008

Linton, J.D., Klassen, R., Jayaraman, V., 2007. Sustainable supply chains: An introduction. Journal of Operations Management, Supply Chain Management in a Sustainable EnvironmentSpecial Issue on Frontiers of Empirical Supply Chain Research 25, 1075-1082. doi:10.1016/j.jom.2007.01.012

McFarlane, D., Giannikas, V., Lu, W., 2016. Intelligent logistics: Involving the customer. Computers in Industry. doi:10.1016/j.compind.2015.10.002

McFarlane, D., Giannikas, V., Wong, A.C.Y., Harrison, M., 2013. Product intelligence in industrial control: Theory and practice. Annual Reviews in Control 37, 69-88. doi:10.1016/j.arcontrol.2013.03.003

Meyer, G.G., Främling, K., Holmström, J., 2009. Intelligent Products: A survey. Computers in Industry 60, 137-148. doi:10.1016/j.compind.2008.12.005

Montreuil, B., 2011. Toward a Physical Internet: meeting the global logistics sustainability grand challenge. Logistics Research 3, 71-87. doi:10.1007/s12159-011-0045-x

Morariu, C., Morariu, O., Borangiu, T., 2013a. Customer order management in service oriented holonic manufacturing. Computers in Industry 64, 1061-1072. doi:10.1016/j.compind.2013.07.007

Morariu, C., Morariu, O., Borangiu, T., Sallez, Y., 2013b. Formalized Information Representation for Intelligent Products in Service-Oriented Manufacturing. Presented at the Intelligent Manufacturing Systems, pp. 318-323. 
Morariu, O., Borangiu, T., Raileanu, S., 2015. vMES: Virtualization aware manufacturing execution system. Computers in Industry 67, 27-37. doi:10.1016/j.compind.2014.11.003

Morariu, O., Borangiu, T., Raileanu, S., Morariu, C., 2016. Redundancy and scalability for virtualized MES systems with programmable infrastructure. Computers in Industry. doi:10.1016/j.compind.2015.08.011

Morariu, O., Morariu, C., Borangiu, T., 2014. Shop-floor resource virtualization layer with private cloud support. Journal of Intelligent Manufacturing 1-16. doi:10.1007/s10845-014-0878-7

Morel, G., Panetto, H., Zaremba, M., Mayer, F., 2003. Manufacturing Enterprise Control and Management System Engineering: paradigms and open issues. Annual Reviews in Control 27, 199-209. doi:10.1016/j.arcontrol.2003.09.003

Negri, E., Fumagalli, L., Garetti, M., Tanca, L., 2016. Requirements and languages for the semantic representation of manufacturing systems. Computers in Industry. doi:10.1016/j.compind.2015.10.009

Novas, J.M., Bahtiar, R., Van Belle, J., Valckenaers, P., 2012. An Approach for the Integration of a Scheduling System and a Multi-Agent Manufacturing Execution System. towards a Collaborative Framework. Presented at the Information Control Problems in Manufacturing, pp. 728-733.

Pach, C., Berger, T., Sallez, Y., Trentesaux, D., 2015. Reactive control of overall power consumption in flexible manufacturing systems scheduling: A Potential Fields model. Control Engineering Practice 44, 193-208. doi:10.1016/j.conengprac.2015.08.003

Panescu, D., Pascal, C., 2016. Holonic coordination obtained by joining the contract net protocol with constraint satisfaction. Computers in Industry. doi:10.1016/j.compind.2015.08.010

Prabhu, V.V., 2012. Services for Competitive and Sustainable Manufacturing in the Smart Grid, in: Borangiu, T., Thomas, A., Trentesaux, D. (Eds.), Service Orientation in Holonic and Multi-Agent Manufacturing Control, Studies in Computational Intelligence. Springer Berlin Heidelberg, pp. 227-240.

Prabhu, V.V., Jeon, H.W., Taisch, M., 2013. Simulation Modelling of Energy Dynamics in Discrete Manufacturing Systems, in: Borangiu, T., Thomas, A., Trentesaux, D. (Eds.), Service Orientation in Holonic and Multi Agent Manufacturing and Robotics, Studies in Computational Intelligence. Springer Berlin Heidelberg, pp. 293-311.

Prabhu, V.V., Trentesaux, D., Taisch, M., 2015. Energy-aware manufacturing operations. International Journal of Production Research 53, 6994-7004. doi:10.1080/00207543.2015.1100766

Raco, M., 2007. Securing Sustainable Communities Citizenship, Safety and Sustainability in the New Urban Planning. European Urban and Regional Studies 14, 305-320. doi:10.1177/0969776407081164

Raileanu, S., Anton, F., latan, A., Borangiu, T., Anton, S., Morariu, O., 2015. Resource scheduling based on energy consumption for sustainable manufacturing. Journal of Intelligent Manufacturing 1-12. doi:10.1007/s10845-015-1142-5

Raileanu, S., Borangiu, T., Radulescu, S., 2014. Towards an Ontology for Distributed Manufacturing Control, in: Borangiu, T., Trentesaux, D., Thomas, A. (Eds.), Service Orientation in Holonic and Multi-Agent Manufacturing and Robotics, Studies in Computational Intelligence. Springer International Publishing, pp. 97-109.

Sallez, Y., Berger, T., Deneux, D., Trentesaux, D., 2010. The lifecycle of active and intelligent products: The augmentation concept. International Journal of Computer Integrated Manufacturing 23, 905-924. doi:10.1080/0951192X.2010.490275

Sallez, Y., Pan, S., Montreuil, B., Berger, T., Ballot, E., 2016. On the activeness of intelligent Physical Internet containers. Computers in Industry. doi:10.1016/j.compind.2015.12.006

Sanislav, T., Mois, G., Miclea, L., 2016. An approach to model dependability of cyber-physical systems. Microprocessors and Microsystems 41, 67-76. doi:10.1016/j.micpro.2015.11.021

Scanff, E., Feldman, K.L., Ghelam, S., Sandborn, P., Glade, M., Foucher, B., 2007. Life cycle cost impact of using prognostic health management (PHM) for helicopter avionics. Microelectronics Reliability, Electronic system prognostics and health managementThermal, mechanical and multi-physics simulation and experiments in micro-electronics and micro-systems (EuroSimE 2006) 47, 18571864. doi:10.1016/j.microrel.2007.02.014

Tang, D., Dai, M., Salido, M.A., Giret, A., 2016. Energy-efficient dynamic scheduling for a flexible flow shop using an improved particle swarm optimization. Computers in Industry. doi:10.1016/j.compind.2015.10.001 
Thomas, A., Trentesaux, D., 2014. Are Intelligent Manufacturing Systems Sustainable?, in: Borangiu, T., Trentesaux, D., Thomas, A. (Eds.), Service Orientation in Holonic and Multi-Agent Manufacturing and Robotics, Studies in Computational Intelligence. Springer International Publishing, pp. 3-14.

Thomas, A., Trentesaux, D., Valckenaers, P., 2012. Intelligent distributed production control. Journal of Intelligent Manufacturing 23, 2507-2512. doi:10.1007/s10845-011-0601-x

Trentesaux, D., 2009. Distributed control of production systems. Engineering Applications of Artificial Intelligence 22, 971-978. doi:10.1016/j.engappai.2009.05.001

Trentesaux, D., Giret, A., 2015. Go-green manufacturing holons: A step towards sustainable manufacturing operations control. Manufacturing Letters 5, 29-33. doi:10.1016/j.mfglet.2015.07.003

Trentesaux, D., Millot, P., 2016. A human-centered design to break the myth of the "Magic Human » in Intelligent Manufacturing Systems, in: Service Orientation in Holonic and Multi-Agent Manufacturing, Studies in Computational Intelligence. Springer, pp. 103-114.

United Nations, 1987. Report of the World Commission on Environment and Development: Our Common Future.

Valckenaers, P., Van Brussel, H., 2005. Holonic Manufacturing Execution Systems. CIRP Annals Manufacturing Technology 54, 427-432. doi:10.1016/S0007-8506(07)60137-1

van Gorp, A., 2007. Ethical issues in engineering design processes; regulative frameworks for safety and sustainability. Design Studies 28, 117-131. doi:10.1016/j.destud.2006.11.002

Wang, S., Liu, Z., Sun, Q., Zou, H., Yang, F., 2012. Towards an accurate evaluation of quality of cloud service in service-oriented cloud computing. Journal of Intelligent Manufacturing 25, 283-291. doi:10.1007/s10845-012-0661-6

Wang, X.V., Xu, X.W., 2013. ICMS: A Cloud-Based Manufacturing System, in: Li, W., Mehnen, J. (Eds.), Cloud Manufacturing, Springer Series in Advanced Manufacturing. Springer London, pp. 1-22.

Wu, L., Yang, C., 2010. A Solution of Manufacturing Resources Sharing in Cloud Computing Environment, in: Luo, Y. (Ed.), Cooperative Design, Visualization, and Engineering, Lecture Notes in Computer Science. Springer Berlin Heidelberg, pp. 247-252.

$\mathrm{Xu}, \mathrm{X}$., 2012. From cloud computing to cloud manufacturing. Robotics and Computer-Integrated Manufacturing 28, 75-86. doi:10.1016/j.rcim.2011.07.002

Zamojski, W., Mazurkiewicz, J., Sugier, J., Walkowiak, T., Kacprzyk, J. (Eds.), 2012. Complex Systems and Dependability, Advances in Intelligent and Soft Computing. Springer Berlin Heidelberg, Berlin, Heidelberg.

Zhang, Y., Luo, X., Buis, J.J., Sutherland, J.W., 2015. LCA-oriented semantic representation for the product life cycle. Journal of Cleaner Production 86, 146-162. doi:10.1016/j.jclepro.2014.08.053

Zhu, H., 2012. Reliability and availability analysis for large networking system. Presented at the Reliability and Maintainability Symposium (RAMS), 2012 Proceedings - Annual, IEEE, pp. 1-6. doi:10.1109/RAMS.2012.6175453 